可視化情報 Vol.19 Suppl. No1（1999 年 7 月）

\title{
135 速度勾配テンソルを用いた粒子点上での物理情報の抽出
}

\author{
石川 正明 ○(福井大·院)，村井 祐一(福井大·工)， \\ 太田 淳一 (福井大・I)，山本富士夫(福井大・エ)
}

Extraction of Physical Information at Particle Points from Velocity Gradient Tensor

Masa-aki ISHIKAWA, Yuichi MURAI, Junichi OHTA, and Fujio YAMAMOTO

ABSTRACT

We have developed the velocity gradient tensor method (VGT) which is a PTV algorithm. When the VGT method is used at particle points, we can simultaneously get both of the velocity vectors and velocity gradient tensor. It means that physical information can be directly extracted at particle points. The purpose of this study is to propose a new technique of the extraction of physical information at particle points from the velocity gradient tensor. The processing is applied to the vortex flow and PIVStandard Image, the performance is examined from the precision for extraction of vorticity and stream function.

Keywords : Velocity Gradient Tensor, Vorticity, Stream Function, PIV-Standard Image

\section{1.はじめに}

我々はPTV アルゴリズムとして変形成分を扱うことの できる速度勾配テンソルを用いることにより，従来から多く 利用されるPTV アルゴリズムに比べて高い正対応率を持 つアルゴリズム [ 速度勾配テンソル法 ] を提案してきた ${ }^{(1)}$. この方法では粒子点上の速度ベクトルを求める際に，局所 的な速度勾配テンソル（空間微分量）が同時に算出される. 従って，この速度ベクトルと速度勾配テンソルを有効に用 いれば，粒子点上または任意点上の物理情報を直接的に抽 出することができる，そこで本報告では速度勾配テンソル 法のテクニックを用いて粒子点または任意点における速度 および速度勾配テンソルを算出する方法を提案する．また この手法の性能を渦流れと可視化情報学会で提案されてい るPIV 標準画像に適用して渦度と流れ関数の抽出精度につ いて評価を行う。

\section{2. 速度勾配テンソルの算出}

PTVによって得られる離散的な速度ベクトル情報から他 の物理量抽出するために，渦度や流れ関数など一次の空間 微分量，つまり速度勾配テンソルを算出する必要がある。そ こで，粒子点 $\overrightarrow{x t}$ を中とする微小な半径 $r$ をとり，その 内にある粒子点 $\overrightarrow{x_{\imath}}$ の速度 $\overrightarrow{u_{\imath}}$ を用いて一次の Taylor 展開 をとると速度勾配テンソルを含む次式が得られる.

$$
\begin{gathered}
\overrightarrow{u_{i}}=\vec{u} \vec{l}+\delta u\left(\overrightarrow{x_{I}}\right)\left(\overrightarrow{x_{i}}-\overrightarrow{x_{I}}\right) \\
\delta u\left(\overrightarrow{x_{I}}\right)=\left(\begin{array}{lll}
\frac{\partial u}{\partial x} & \frac{\partial u}{\partial y} & \frac{\partial u}{\partial z} \\
\frac{\partial v}{\partial x} & \frac{\partial v}{\partial y} & \frac{\partial v}{\partial z} \\
\frac{\partial w}{\partial x} & \frac{\partial w}{\partial y} & \frac{\partial w}{\partial z}
\end{array}\right)=\left(a_{k l}\right) \\
(k, l=1,2,3)
\end{gathered}
$$

$\left(a_{k l}\right)$ はマトリックスを表し， $a_{k l}$ は $(k, l)$ のマトリックス の成分を表している.

ここで,この半径 $r$ 内に存在するすべてのベクトルに対 し，Eq. (1)による残差 $R$ は次式にように与えられる.

$$
R=\sum_{i=1}^{n}\left\|-\left(\overrightarrow{u_{i}}-\overrightarrow{u_{I}}\right)+\delta u(\vec{x})\left(\overrightarrow{x_{i}}-\overrightarrow{x_{I}}\right)\right\|^{2}
$$

上式において未知数である速度勾配テンソル $\delta u\left(\overrightarrow{x_{I}}\right)$ の 各成分を偏微分した次式を用いて最小二乗法により速度勾 配テンソル $\delta u\left(\overrightarrow{x_{I}}\right)$ を算出する.

$$
\frac{\partial R}{\partial a_{k l}}=0
$$

例えば，二次元計測の場合では，速度勾配テンソルの成 分は以下の 4 つの未知数 $\left(a_{11}, a_{12}, a_{21}, a_{22}\right)$ を用いて計 算される.

$$
\frac{\partial R}{\partial a_{11}}=\frac{\partial R}{\partial a_{12}}=\frac{\partial R}{\partial a_{21}}=\frac{\partial R}{\partial a_{22}}=0
$$

また粒子点以外の任意点（格子点上）に対しても本処理 は適用することができる，それには末知数に任意点上の速 度ベクトルを増やすだけで Eq. (2) に最小二乗法に適用す ることにより，次式から任意点上の速度ベクトルと速度勾 配テンソルが同時に算出できる.

$$
\frac{\partial R}{\partial(\vec{u} \xi)_{k}}=\frac{\partial R}{\partial a_{k l}}=0
$$

\section{3. 結果及び考察}

本手法の性能を評価するために物理情報量として速度勾 配テンソルから算出できる渦度 $\omega$ と流れ関数 $\psi$ の 2 つを 用いる。

ただし， $\delta u\left(\overrightarrow{x_{I}}\right)$ は粒子点 $\overrightarrow{x I}$ 上の速度勾配テンンルであり， 


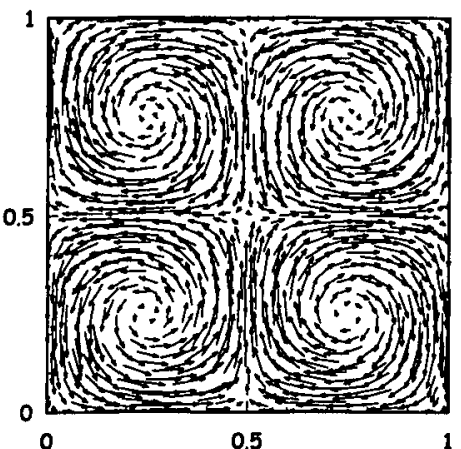

(a) Velocity map

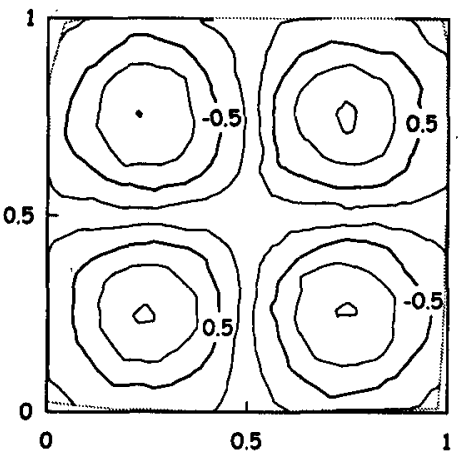

(b) Vorticity

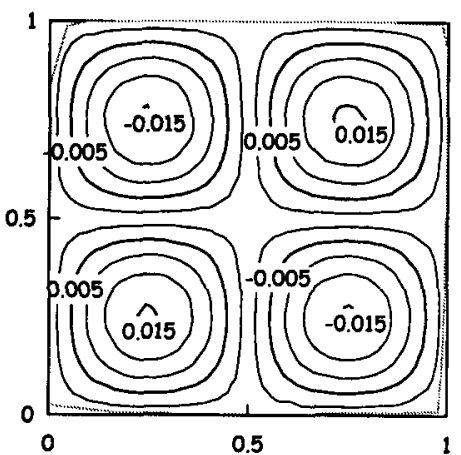

(c) Stream Function

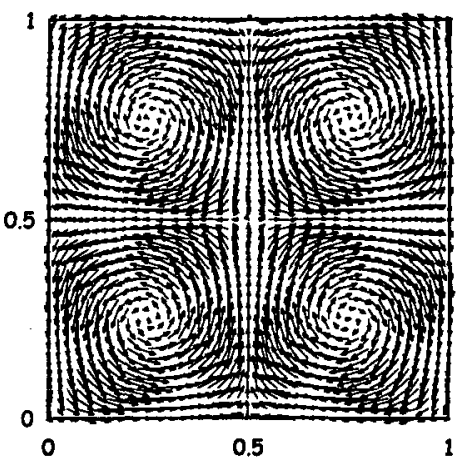

(d) Velocity Map (Rearranged by IDR)

Calculated data obtained by the present method

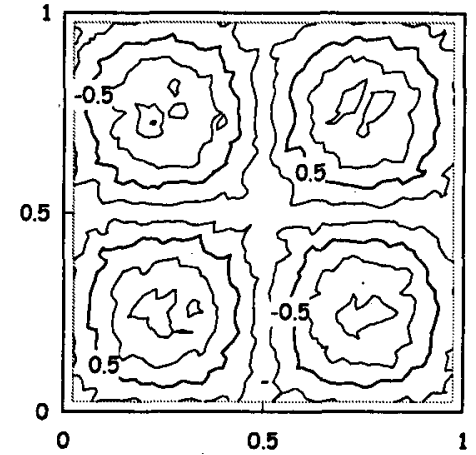

(e) vorticity

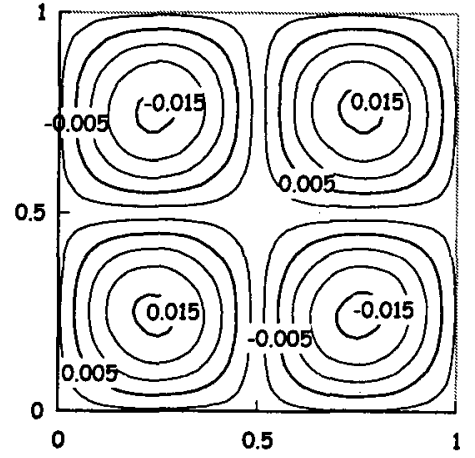

(f) Stream Function

Calculated data obtained by the IDR method

Fig. 1 Contour of vorticity and stream function

\section{1 渦度と流れ関数の算出方法}

渦度 $\omega$ は次式で示すように Eq. (2) で与えられる速度勾 配テンソルから直接抽出できる。

$$
\omega=\frac{\partial v}{\partial x}-\frac{\partial u}{\partial y}=a_{21}-a_{12}
$$

また流れ関数 $\psi$ は次式による渦度 $\omega$ と流れ関数 $\psi$ の関 係式を用いて算出する。

$$
\nabla^{2} \psi=-\omega
$$

ここである粒子点 $o$ を原点として $(\Delta x, \Delta y)$ ずれた点 $i$ における流れ関数 $\psi_{i}$ は 2 次の Taylor 展開により次式で与 えられる.

$$
\begin{aligned}
\psi_{i}= & \psi_{o}+\frac{\partial \psi_{o}}{\partial x} \Delta x+\frac{\partial \psi_{o}}{\partial y} \Delta y+\frac{1}{2} \frac{\partial^{2} \psi_{o}}{\partial x^{2}}(\Delta x)^{2} \\
+ & \frac{\partial^{2} \psi_{o}}{\partial x \partial y} \Delta x \Delta y+\frac{1}{2} \frac{\partial^{2} \psi_{o}}{\partial y^{2}}(\Delta y)^{2} \\
\psi_{i}= & \psi_{\circ}-v \Delta x+u \Delta y+\frac{\partial^{2} \psi_{o}}{\partial x \partial y} \Delta x \Delta y \\
+ & \frac{1}{2}\left\{\frac{\partial^{2} \psi_{o}}{\partial x^{2}}\left((\Delta x)^{2}-(\Delta y)^{2}\right)-\omega_{o}(\Delta y)^{2}\right\}(9) \\
& \left(\because E q .(8), u=\frac{\partial \psi_{o}}{\partial y}, v=-\frac{\partial \psi_{o}}{\partial x}\right)
\end{aligned}
$$

しかし流れ関数 $\psi_{i}$ は末知数であり、このままでは流れ 関数を解くことはできない，そこですべての流れ関数の 初期条件を $\psi_{i}=0$ とおく. そして上式の 3 つの未知数 $\left(\psi_{o}, \frac{\partial^{2} \psi_{o}}{\partial x^{2}}, \frac{\partial^{2} \psi_{o}}{\partial x \partial y}\right)$ を Eq. (9) において逐次残差法を適用
し，収束判定条件を満たすまで繰り返し計算を行い，流れ 関数 $\psi$ 。を求める.

\section{2 渦流れへの適用}

本手法の性能を評価するためには任意点上の渦度 $\omega$ と流 れ関数 $\psi$ が既知である必要がある. そこで速度, 渦度及び 流れ関数がすべて任意点上で既知となる次式で表せる渦流 れに適用した。

$$
\begin{aligned}
u & =W \sin \left(2 \pi k \frac{x}{L}\right) \cos \left(2 \pi k \frac{y}{L}\right) \\
v & =-W \cos \left(2 \pi k \frac{x}{L}\right) \sin \left(2 \pi k \frac{y}{L}\right) \\
\omega & =\frac{4 \pi k W}{L} \sin \left(2 \pi k \frac{x}{L}\right) \sin \left(2 \pi k \frac{y}{L}\right) \\
\psi & =\frac{W L}{2 \pi k} \sin \left(2 \pi k \frac{x}{L}\right) \sin \left(2 \pi k \frac{y}{L}\right)
\end{aligned}
$$

ここで，Wは速度の振幅， $L$ は正方領域の一辺の長さ， $(x, y)$ は正方領域内の座標, $(u, v)$ は座標 $(x, y)$ 上の速 度ベクトル， $\omega$ は座標 $(x, y)$ 上の渦度， $\psi$ は座標 $(x, y)$ 上の流れ関数である。

またここで用いている渦流れは N-S 方程式の要素解の一 種であり，少ないパラメータ（波数 $k$, ベクトル数 $N$ ) で流 れ場が表現され，本手法の性能を評価するのに好適である。 渦流れのシミュレーション・データを作成するに当たり，パ ラメータは波数 $k=0.5 \sim 5$, 刻み 0.5 の 10 段階, ベクト 儿数 $N=100,400,900,1600,2500$ の 5 段階とした。 また 速度の振幅 $W=0.1$, 渦流れの領域の一辺 $L=1$ とした. また計算時に用いる近傍領域の半径 $r$ の設定は重要なパラ 


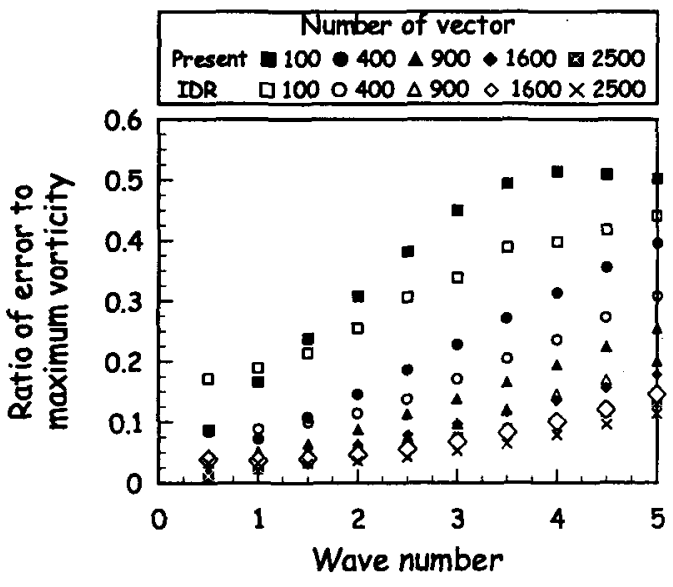

(a) Vorticity

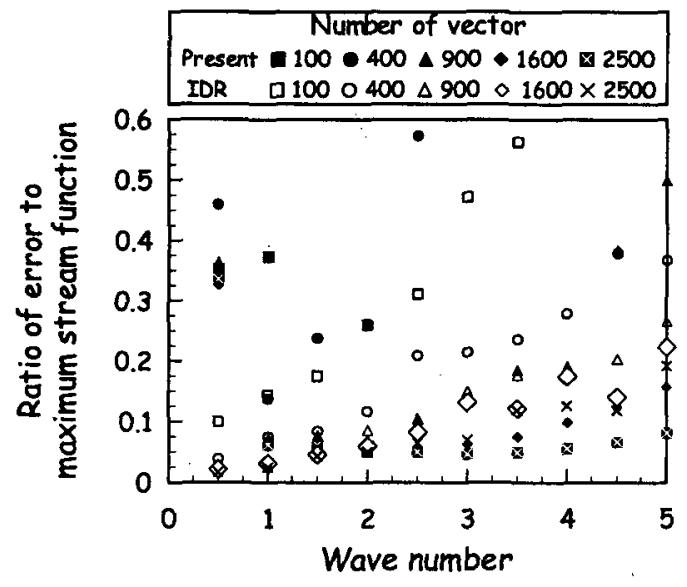

(b) Stream function

Fig. 2 Relation between ratio of error to maximum physical information and parameters

メータ因子であるが，ここではその半径の円内に含まれる ベクトル数が $n=10$ となるよう, $r=\sqrt{n L^{2} / \pi N}$ で与. えた.

Fig. I (a) に波数 $k=1$, ベクトル数 $N=900$ の場合 の速度ベクトル図を示す.この速度べクトルから本手法に よって得られた渦度と流れ関数の等高線図をそれぞれ Fig. 1 (b)，(c) に示す。.この比較対象の一例として，Fig. 1 (d) に距離の逆数による再配圈法 (以下 IDR と略す) で補間さ れた速度ベクトル図を示す. 再配置後の速度ベクトルから得 られた渦度と流れ関数の等高線図をそれぞれ Fig. 1 (e)，(f) に示す，ただし，IDR 法に用いた格子は $41 \times 41$ の正方形 格子であり，渦度は Eq. (7) の微分式を 4 近傍格子による 中心差分によって求めた. また流れ関数は座標 $(0,0)$ を初期 值 $\psi=0$ とおき，そこを基淮に稍分 $\left(\psi=\int(-v d x+u d y)\right)$ によって得た.

Fig. 1 (b), (e) の渦度の等高線結果より而手法とも 4 つ の渦構造が確認できるものの，本手法の方が滑らかな等高 線となっている．この差異は，本手法が近傍領域内の四方 八方の速度ベクトルを採用するのに対し，IDR 法の計算で は着目した格子点の 4 近傍の中心差分を用いて算出するた めに対角方向に善が生じやすいことにある．また再配直法 で用いられた速度ベクトル数 $N=900$ に比べ，格子数が 1681 と多いために再配置法による精度の低下も考えられる. そして本手法では, 若干渦が領域の中心部に茼っているこ とがわかる，それは端の領域でベクトル分布の偏りが最も 大きいためであると考えられる.

Fig. 1 (c), (f) の流れ関数の等高線結果では両手法とも 4 つの渦の流線が滑らかに得られて，有意な差異のないこと がわかる。

Fig. 1 では視覚的判断による定性的な特徵を述べたが， 本手法の性能を定量的に検証するために Eq. (14), (15)に よる誤差評価を行った.

$$
E_{\phi}^{2}=\frac{\sum_{k=1}^{N}\left(\phi_{t h}-\phi_{c a l}\right)^{2}}{N}
$$

$$
E_{\phi}^{\prime}=\frac{E_{\phi}}{\phi_{\max }}
$$

ここで $\phi$ は物理量（渦度 $\omega ，$ 流れ関数 $\psi$ )を表しており， 添字 $t h$ は物理量の真值を表し，添字 cal は物理量の計算值 を表し，添字 $\max$ は物理量の最大值を表している.

Fig. 2 (a)，(b) はそれぞれ渦度及び流れ関数に対する䛊 差の比 $E_{\phi}{ }^{\prime}$ を示している. 横軸には波数を，綎軸にはそれ らの誤差の比をとり、塗りつぶされた記号はそれぞれ本手 法，白抜きの記号はそれぞれ IDR 法を示す．数字は PTV データのベクトル数である。この結果では本手法のみ試行 回数 100 回による平均值を表す.

Fig. 2 (a) から，渦度については，両手法とも波数が少 なくかつべクトル数が多い場合に誤差の比の低い良好な結 果が得られることが分かる．波数 $k=1$ 以下では本手法は IDR 法に比べ誤差の低い結果が得られ，それ以上では逆に IDR 法の方が本手法に比べ誤差の低い結果が得られる.

また Fig. 2 (b) の流れ関数の結果では，波数 $k=0.5$ を 除いて波数が少なく，かつべクトル数が多い場合に誤差の 比の低い良好な結果が得られることが分かる。本手法では 波数 $k=0.5$ の場合に波数が低いにも関わらずその誤差の 比が高くなる結果が得られている.これは波数 $k=0.5 の$ 場合に流れ関数の真值が正の值のみであることと，本手法 では流れ関数を Eq. (9) の逐次残差法により解いているた めに流れ関数の初期值 $\psi_{i}=0$ を中心にして流れ関数が分布 し，真值より最大值の半值分がずれるためである.しかし 波数 $k=0.5$ の誤差の比が高いからといって波数 $k=1$ の 誤差の比と比較して精度が落ちているわけではない，そし て本手法ではべクトル数の少ない $N=100,400$ では誤差 が大きい.しかしベクトル数が $N=1600 ， 2500$ と多い場 合では IDR 法と比較しても変わらないほど誤差の低い結果 が得られている.このことから速度ベクトルが密に分布す れば，小さな誤差で物理情報量を抽出できることがわかる．

\section{3 PIV 標準画潒への適用}

前述では渦流れのシミュレーションによって検証を行った 

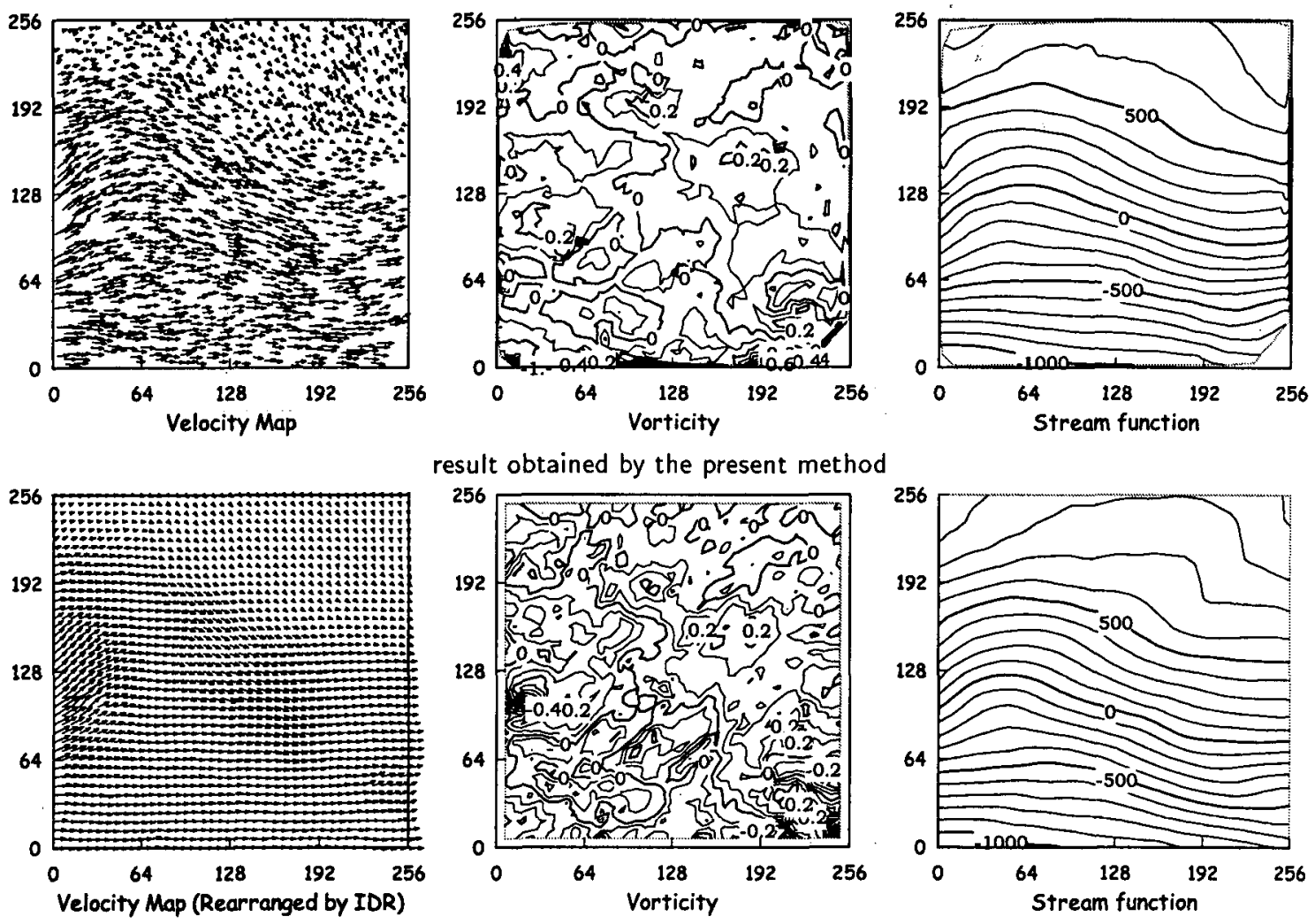

result obtained by the present method
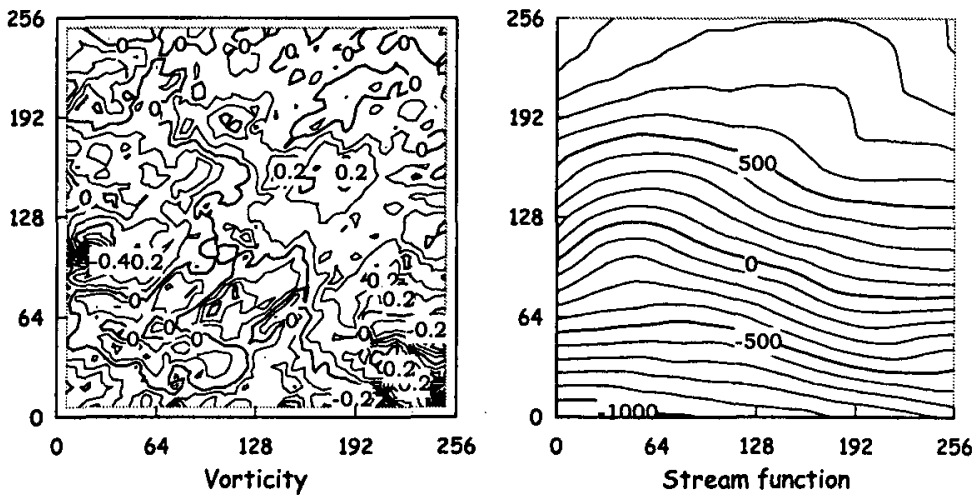

result obtained by IDR method

Fig. 3 Contour of vorticity and stream function for PIV standard image

が，実際の流れ場を模擬するには不十分である．そこで可 視化情報学会で公開されている PIV 標準画像 ${ }^{(2)}$ を用いて 渦度と流れ関数の抽出精度を検討した．対象とする画像に は, PIV 標準画像 No.01（粒子数 $N=5000$, 最大移動距 離 = 15pixels）を用いた．まず粒子点を得るためにラプラ シアン処理をし，二値化処理から粒子像を抽出し，粒子点座 標を算出した。統いて速度ベクトルを得るためにVGT 法 (1)を採用した。 そこでは過誤ベクトル除去のため，周りの 速度べクトルの角度と大きさの中問值が許容值 $\left(45^{\circ}\right)$ を越 えるものを過誤ベクトルと判定した. それによって得られた 速度べクトル図を Fig. 3 (a) に示す.この速度べクトルを 本手法に適用した場合の渦度と流れ関数の等高線図を Fig. 3 (b), (c) に示す. またその比較のために IDR 法によって 得られた再配㯰結果を Fig. 3 (d) に，その再配置結果から 渦度及び流れ関数の等高線図を Fig. 3 (e), (f) に示す.

これらの結果から流れ関数の等高線図はほほ同様な良好 な結果が得られたが，渦度の等高線図は両手法を比較する には十分な結果は得られなかった。この理由は，粒子の重心 座標算出精度にあると考えている. 即ち, 今回対象とした PIV 標準画像では，流れ場を保有する渦度が小さいために， 1 pixel 程度の粒子重心座標誤差が相対的に大きな渦度の誤 差となって表される. 今後はVGTによる物理情報の抽出 において，粒子重心座標の計測誤差の影響を調査したい。

\section{4. 結論}

本論文では PTV アルゴリズムである速度勾配テンソル 法のテクニックを用いて離散的な粒子点上での速度勾配テ ンソルから物理情報を抽出する方法を提案した．またその 性能は渦流れと可視化情報学会で提案されている PIV 標準 画像を用いて，渦度と流れ関数により評価を行なった。

なお，今後はラプラス方程式再配置法 (3) など後処理に 基づく方法との比較・検討を進める必要がある.

\section{謝辞}

本手法の適用にあたり PIV 標淮画像を作成及び提供され ている東京大学 岡本孝司助教授に深く感謝します。

\section{参考文献}

(1) ISHIKAWA, M., MURAI, Y., IGUCHI, M., WADA, A., and YAMAMOTO, F., "The performance of the velocity gradient tenser algorithm for PIV", Proc. of VSJSPIE'98, (1998,12), AB092.

（2）岡本孝司，佐賀徹雄，小林敏雄，西尾茂，“PIV 標準画像の 粠築（第 1 報：標海画像生成手法の検討）"，可視化情報論文 集, $(1997,7)$, Vol. 17, Suppl., No.1, pp. 167 - 170.

（3）村井祐一，井戸健敬，石川正明，山本富士夫，“CFD の手法 を用いた PIV 計測結果のポストプロセッシング法の開発”，日 本機械学会論文集, $(1998,10)$, B, 64-626, pp. 3249 - 3256 . 